Editorial

\title{
Genome-wide association studies in kidney transplantation: Advantages and constraints
}

\section{A R T I C L E I N F O}

\section{Keywords:}

Genome-wide association studies

Kidney transplantation

\begin{abstract}
A B S T R A C T
Since the discovery of the human leukocyte antigen (HLA) system, the role of HLA molecules in the field of transplantation has been appreciated: better matching leads to better graft function. Since then, the association of other genetic polymorphisms with clinical outcome has been investigated in many studies. Genome-wide association studies (GWAS) represent a powerful tool to identify causal genetic variants, by simultaneously analyzing millions of single nucleotide polymorphisms scattered across the genome. GWAS in transplantation may indeed be useful to reveal novel markers that may potentially be involved in the mechanism of allograft rejection and graft failure. However, the relevance of GWAS for risk stratification or donor selection for an individual patient is limited as is already reflected by the fact that many parameters, significant in one study, cannot be confirmed in another one.
\end{abstract}

\section{Introduction}

Human leukocyte antigen (HLA) matching has a beneficial effect on kidney graft survival $[1,2]$. In addition, many other candidate genes beyond HLA loci have been reported to affect kidney transplantation $[3,4]$. Discrepant results among many of those have been reported, although the association between pharmacogenomics and tacrolimus blood concentrations was frequently observed [5].

Genome-wide association study (GWAS) represents an unbiased approach to identify genetic variants, which are associated with human disease. The approach enables analysis of millions of single nucleotide polymorphisms (SNPs) scattered across the genome. GWAS may also provide a robust genomic platform to characterize genetic risk factors of adverse transplant outcome. Here we discuss that GWAS may be applied to identify novel molecules and pathways involved in acute rejection (AR) and to predict transplant outcomes, but that the technology has not yet been proven to provide a useful guidance for treatment of the individual patient.

\section{Treatment of recipients after transplantation}

Despite the application of efficient immunosuppressive drugs, acute rejection episodes still occur in kidney transplant recipients. A rise in serum creatinine may indicate a decreased graft function and a need of further diagnosis by an allograft biopsy. Pulse corticosteroid therapy is the first line of treatment for acute cellular rejection [6,7]. Antibody therapy, such as antithymocyte globulin (ATG) or alemtuzumab, is a more effective approach to normalize kidney function for patients who have more severe forms of acute rejection and/or who do not respond to the pulse steroid treatment [7]. Patients with acute antibody mediated rejection may be treated with plasmapheresis, intravenous immune globulin (IVIG) or rituximab [7]. Recipients with viral disease after transplantation may benefit from a reduction in dosage of immunosuppression [7].

Irrespective of the type of treatment, all therapies have been relying on clinical monitoring in blood serum and urine, and diagnostic assessment in allograft biopsies, rather than on genetic diversity between individuals.

\section{HLA and transplant outcome}

The HLA antigens are the most important histocompatibility antigens involved in alloimmune responses. $\mathrm{T}$ cell mediate rejection (TCMR), characterized by the presence of T cells and inflammatory cells in the interstitium and tubular epithelium of the allograft, may be triggered by three distinct mechanisms. Direct allorecognition is driven by the direct interaction between the $\mathrm{T}$ cell receptor on recipient $\mathrm{T}$ cells and mismatched HLA antigens on donor derived antigen presentation cells (APC). In this process, activated $\mathrm{CD} 4+\mathrm{T}$ cells produce inflammatory cytokines and CD8 + cytotoxic $\mathrm{T}$ cells directly destruct the allograft. At a later time point after transplantation the indirect allorecognition pathway becomes more dominant, whereby donor-derived antigens are processed and presented by recipient APCs to recipient $\mathrm{CD} 4+\mathrm{T}$ cells [8]. Recipient dendritic cells transferred with intact donor HLA can also prime recipient $T$ cells via the semidirect pathway [9]. B cells can be activated after recognizing foreign HLA to differentiate to plasma cells and produce donor specific antibodies. These may lead to allograft destruction, which is termed as antibody mediate rejection (ABMR). The presence of antibodies against donor-specific HLA and of C4d deposition in the tissue represents strong evidence for the diagnosis of ABMR [10]. It is important to recognize that TCMR may be encountered as a single entity and as a mixed form with features 
of ABMR [11].

Matching for the HLA-A, HLA-B, and HLA-DR loci has been recognized as great importance for outcome after organ transplantation [12]. The beneficial effect of HLA matching was challenged by high graft survival rate in living donors [13]. However, the significant effect of HLA matching was still observed under the umbrella of efficient immunosuppressive therapy [2]. Therefore, HLA typing and matching remain crucial for graft and patient survival.

\section{Non-HLA genetics of transplant outcome}

Terasaki estimated that only $18 \%$ of graft loss at 10 years for cadaveric donors can be explained by HLA-related immunologic factors, whereas $38 \%$ was caused by non-HLA factors and $43 \%$ by non-immunological factors [14]. One non-HLA-related risk factor is represented by the human H-Y antigen: a male donor allograft to a female recipient is associated with elevated risk of graft loss after kidney transplantation $[15,16]$. The MHC class I polypeptide-related sequence A (MICA) represent potential non-HLA antigens that may elicit an antibody production. Transplant recipients with pre-existing anti-MICA antibody are reported to have an inferior one year graft survival [17]. A number of studies have shown that the presence of non-HLA antibodies, as identified by protein microarray, is associated with allograft injury [18-20]. In HLA compatible kidney transplantations, mismatching for killer-cell immunoglobulin-like receptors (KIR) and ligands was associated with inferior long term graft survival [21]. In a larger independent study, the effect of KIR-ligand mismatching could not be verified [22].

Pharmacogenetics involves the study of genetic variants in drug metabolizing enzymes and transporters. The relationship between SNPs in the drug metabolizing factor CYP3A5 and tacrolimus trough levels in the blood of transplanted patients has been widely described in literature. Hence, dosing adjustments of tacrolimus should be adjusted according to the CYP3A5 genotype, in order to achieve optimal therapeutic concentrations and to reduce tacrolimus toxicity [23,24]. However, pharmacogenetic tests are hardly adopted in transplant centers to optimize the starting dose of immunosuppression. One of the reasons may be the lack of a relevant impact of pharmaco-genotyping test on transplant outcomes [25-28]. On the other hand, therapeutic drug monitoring is widely accepted to correct for the effect of pharmacogenetic polymorphisms [29].

Most genetic association studies in kidney transplantation have been focused on SNPs located within or flanking the genes encoding for proteins that play a pivotal role in immune responses, including cytokines, chemokines, toll-like receptors, ficolins, and complement components [3,30-35]. Overviews of genetic variants investigated in relation to transplant outcome, especially occurrence of acute rejection, have been reviewed previously [3-5]. Many genetic studies have led to observation of a significant association between candidate SNPs and transplant outcome, but validation of the clinical impact of the same SNPs in follow-up studies often led to inconsistent results. For example, transplant recipients with the complement C3S/S variant (common allele) receiving a kidney allograft with the uncommon variant $\mathrm{C} 3 \mathrm{~F} / \mathrm{F}$ or $\mathrm{C} 3 \mathrm{~F} / \mathrm{S}$ had a beneficial graft outcome, but a larger collaborative study showed that genotypic distribution of C3 alleles does not significantly influence kidney transplantation outcome [34,35]. The inconsistent results may be due to differences in population composition and characteristics, inadequate sample size, lack of statistical correction for multiple testing, and lack of validation in an independent cohort. Currently, no singular candidate SNP has unambiguously shown an association with transplant outcome in both a sufficiently large discovery and validation cohort.

\section{GWAS in transplantation}

The candidate SNP approach, as described above, does not provide complete coverage of all possible variants in the genome, and may be limited to genes with a known or postulated involvement in rejection. GWAS enable simultaneous analysis of millions of SNPs spanning the entire genome, which may provide novel insight in the genetic susceptibility of rejection.

Until this moment, GWAS has been performed occasionally in the transplantation field. In 326 Irish kidney transplant recipients, who received a graft from a deceased donor, O'Brien and colleagues reported the association of two genetic variants with five-year graft function [36]. However, in a validation study of 1638 Caucasians transplant recipients no association of these two particular SNPs could be found with serum creatinine levels and long term graft survival [37]. This highlights the importance of validation in genetic association studies and expansion of sample size, for example by international collaboration, to limit false discovery rates.

A large collaborative GWAS of mostly Belgian and French origin, including 778 European kidney transplant recipients, led to identification of two risk loci associated with TCMR, using a DNA pooling approach [38]. Two variants were identified (rs10846175 and rs7976329) located in the first intron of protein tyrosine phosphatase receptor type $\mathrm{O}$ and one variant (rs10765602) located upstream of coiled-coil domain containing 67 , which may play a role in signal transduction in the immune synapse. The authors did not determine the precise mechanism how these SNPs act locally or distantly on genes that are involved in the allo-immune response. Furthermore, the pooled DNA approach may not efficiently reduce the standard deviation of an allele frequency, in case confirmation is not performed by genotyping on individual DNA samples [39]. Unfortunately, in our GWAS in 279 kidney transplant recipients (unpublished), a cohort for which we calculated to have sufficient power for validation, we could not confirm the association of these SNPs with biopsy proven acute rejection.

GWAS in African-American kidney transplant recipients led to the identification of two novel CYP3A5 variants (rs10264272 and rs41303343), which were associated with tacrolimus trough levels [23]. The number of loss-of-function alleles were related to increased one year eGFR, but not to acute rejection incidence [23]. Other GWAS in kidney and in heart transplantation have shown association with occurrence of new-onset diabetes after transplantation (NODAT) and cutaneous squamous cell carcinoma after transplantation [40,41]. GWAS in bone marrow transplantation were mainly focused on acute GvHD and minor HLA antigens, providing evidence that genetic disparity is associated with rejection [42]. Unfortunately, minor HLA antigen disparities identified in identical hematopoietic stem-cell transplantation have no effect on death censored graft survival in kidney transplantation [43].

Genomic research in transplantation is more complicated than genomic research of common diseases, because it involves the interaction between the recipient and the donor graft. A small pilot study showed that the number of amino acid mismatches in trans-membrane proteins was negatively correlated with long term allograft function, independent of HLA matching and donor age [44]. Other on-going GWAS in kidney transplantation combined analysis of recipient and donor genomes, such as homozygous loss-of-function variants and nonsynonymous SNP mismatching [45]. These efforts may provide novel insight in the mechanism of rejection.

\section{GWAS: Limitations and requirements}

One of the main limitations to GWAS is the requirement of stringent significance thresholds due to multiple testing, with typically required $P$-value of less than $10^{-8}$ for single SNPs. Fulfilment of such requirement helps in limiting false positive discoveries, but it also considerably reduces the power to detect associated SNPs. The only way to overcome this limitation is to increase the sample size. However, an intrinsic problem associated with a large multicentre GWAS in transplantation is the fact that donor selection and clinical protocols, including kind and 
dose of immunosuppression, will differ, which certainly may affect the outcome. Another drawback is that individual genetic variants, implicated by GWAS, have only a small effect on complex traits [46]. Riancho pointed out that, even after combining all available GWAS from databases on a particular trait, the polymorphisms identified only explain less than $10 \%$ of the susceptibility to the disease [47]. In other words, it seems impossible to explain a complex trait with the aid of a few genetic polymorphisms. A third remark concern the fact that the biological function of many variants identified by GWAS, which are mostly located in none-coding regions of the genome, is unknown. Thus, follow-up mechanistic studies would be required to elucidate the role of genetic variants in the process of allograft rejection.

Overall, GWAS represent a powerful approach to identify genetic variants associated with clinical transplant outcome on the population level, and to further expand our knowledge of the mechanism of rejection and graft failure for developing novel treatment strategies. Risk assessment for the individual patient using this technology is difficult. At present, GWAS approaches have not provided a useful guidance in daily clinical practice for personalized treatment of the transplanted patient.

\section{Disclosure}

The authors declare no competing interests.

\section{Acknowledgements}

J. Yang was awarded financial support from the China Scholarship Council (201306170038).

\section{Reference}

[1] G.G. Persijn, B. Cohen, Q. Lansbergen, J. D'Amaro, N. Selwood, A. Wing, J.J. van Rood, Effect of HLA-A and HLA-B matching on survival of grafts and recipients after renal transplantation, N. Engl. J. Med. 307 (15) (1982) 905-908.

[2] F.H. Claas, D.L. Roelen, M.K. Dankers, G.G. Persijn, I.I. Doxiadis, A critical appraisal of HLA matching in today's renal transplantation, Transplant. Rev. 18 (2) (2004) 96-102.

[3] B. Almoguera, A. Shaked, B. Keating, Transplantation genetics: current status and prospects, Am. J. Transplant. 14 (4) (2014) 764-778.

[4] A.S. Goldfarb-Rumyantzev, N. Naiman, Genetic predictors of acute renal transplant rejection, Nephrol. Dial. Transplant. 25 (4) (2010) 1039-1047.

[5] C.R. Dorr, W.S. Oetting, P.A. Jacobson, A.K. Israni, Genetics of acute rejection after kidney transplantation, Transpl. Int. 31 (3) (2018) 263-277.

[6] M. Ganji, B. Boroumand, Acute Cell. Reject. Iran J Kidney Dis. 1 (2) (2007) 54-56.

[7] B.L. Kasiske, M.G. Zeier, J.R. Chapman, J.C. Craig, H. Ekberg, C.A. Garvey, M.D. Green, V. Jha, M.A. Josephson, B.A. Kiberd, KDIGO clinical practice guideline for the care of kidney transplant recipients: a summary, Kidney Int. 77 (4) (2010) 299-311.

[8] K.J. Wood, R. Goto, Mechanisms of rejection: current perspectives, Transplantation 93 (1) (2012) 1-10.

[9] L.A. Smyth, O.B. Herrera, D. Golshayan, G. Lombardi, R.I. Lechler, A novel pathway of antigen presentation by dendritic and endothelial cells: implications for allorecognition and infectious diseases, Transplantation 82 (2006) S15-S18.

[10] A. Loupy, M. Haas, K. Solez, L. Racusen, D. Glotz, D. Seron, B. Nankivell, R. Colvin, M. Afrouzian, E. Akalin, The Banff 2015 kidney meeting report: current challenges in rejection classification and prospects for adopting molecular pathology, Am. J. Transplant. 17 (1) (2017) 28-41.

[11] P. Randhawa, T-cell-mediated rejection of the kidney in the era of donor-specific antibodies: diagnostic challenges and clinical significance, Curr. Opin. Organ Transplant. 20 (3) (2015) 325-332.

[12] S. Takemoto, F.K. Port, F.H. Claas, R.J. Duquesnoy, HLA matching for kidney transplantation, Hum. Immunol. 65 (12) (2004) 1489-1505.

[13] P.I. Terasaki, J.M. Cecka, D.W. Gjertson, S. Takemoto, High survival rates of kidney transplants from spousal and living unrelated donors, N. Engl. J. Med. 333 (6) (1995) 333-336.

[14] P. Terasaki, Deduction of the fraction of immunologic and non-immunologic failure in cadaver donor transplants, Clin. Transpl. (2003) 449-452.

[15] A. Gratwohl, B. Döhler, M. Stern, G. Opelz, HY as a minor histocompatibility antigen in kidney transplantation: a retrospective cohort study, Lancet 372 (9632) (2008) 49-53.

[16] S.J. Kim, J.S. Gill, HY incompatibility predicts short-term outcomes for kidney transplant recipients, J. Am. Soc. Nephrol. 20 (9) (2009) 2025-2033.

[17] Y. Zou, P. Stastny, C. Süsal, B. Döhler, G. Opelz, Antibodies against MICA antigens and kidney-transplant rejection, N. Engl. J. Med. 357 (13) (2007) 1293-1300.

[18] S.M. Sutherland, L. Li, T.K. Sigdel, P.P. Wadia, D.B. Miklos, A.J. Butte, M.M. Sarwal,
Protein microarrays identify antibodies to protein kinase $\mathrm{C} \zeta$ that are associated with a greater risk of allograft loss in pediatric renal transplant recipients, Kidney Int. 76 (12) (2009) 1277-1283.

[19] T.K. Sigdel, L. Li, T.Q. Tran, P. Khatri, M. Naesens, P. Sansanwal, H. Dai, S.-c. Hsieh, M.M. Sarwal, Non-HLA antibodies to immunogenic epitopes predict the evolution of chronic renal allograft injury, J. Am. Soc. Nephrol. 23 (4) (2012) 750-763.

[20] A.M. Jackson, T.K. Sigdel, M. Delville, S.-C. Hsieh, H. Dai, S. Bagnasco, R.A. Montgomery, M.M. Sarwal, Endothelial cell antibodies associated with novel targets and increased rejection, J. Am. Soc. Nephrol. 26 (5) (2015) 1161-1171.

[21] J. van Bergen, A. Thompson, G. Haasnoot, J. Roodnat, J. de Fijter, F. Claas, F. Koning, I. Doxiadis, KIR-ligand mismatches are associated with reduced longterm graft survival in HLA-compatible kidney transplantation, Am. J. Transplant. 11 (9) (2011) 1959-1964.

[22] T. Tran, C. Unterrainer, G. Fiedler, B. Döhler, S. Scherer, A. Ruhenstroth, M. Adamek, D. Middleton, G. Opelz, No impact of KIR-ligand mismatch on allograft outcome in HLA-compatible kidney transplantation, Am. J. Transplant. 13 (4) (2013) 1063-1068.

[23] W. Oetting, D. Schladt, W. Guan, M. Miller, R. Remmel, C. Dorr, K. Sanghavi, R. Mannon, B. Herrera, A. Matas, Genomewide association study of tacrolimus concentrations in African American kidney transplant recipients identifies multiple CYP3A5 alleles, Am. J. Transplant. 16 (2) (2016) 574-582.

[24] L. Rojas, I. Neumann, M.J. Herrero, V. Boso, J. Reig, J.L. Poveda, J. Megías, S. Bea, S. Aliño, Effect of CYP3A5* 3 on kidney transplant recipients treated with tacrolimus: a systematic review and meta-analysis of observational studies, Pharmacogenom. J. 15 (1) (2015) 38.

[25] F. Glowacki, A. Lionet, D. Buob, M. Labalette, D. Allorge, F. Provôt, M. Hazzan, C. Noël, F. Broly, C. Cauffiez, CYP3A5 and ABCB1 polymorphisms in donor and recipient: impact on Tacrolimus dose requirements and clinical outcome after renal transplantation, Nephrol. Dial. Transplant. 26 (9) (2011) 3046-3050.

[26] D.A. Hesselink, R.H. van Schaik, M. van Agteren, J.W. de Fijter, A. Hartmann, M. Zeier, K. Budde, D.R. Kuypers, P. Pisarski, Y. Le Meur, CYP3A5 genotype is not associated with a higher risk of acute rejection in tacrolimus-treated renal transplant recipients, Pharmacogenet. Genomics 18 (4) (2008) 339-348.

[27] S. Bandur, J. Petrasek, P. Hribova, E. Novotna, I. Brabcova, O. Viklicky, Haplotypic structure of ABCB1/MDR1 gene modifies the risk of the acute allograft rejection in renal transplant recipients, Transplantation 86 (9) (2008) 1206-1213.

[28] A. Flahault, D. Anglicheau, M.-A. Loriot, E. Thervet, N. Pallet, Clinical impact of the CYP3A5 6986A > G allelic variant on kidney transplantation outcomes, Pharmacogenomics 18 (2) (2017) 165-173.

[29] T. Van Gelder, R.H. Van Schaik, D.A. Hesselink, Pharmacogenetics and immunosuppressive drugs in solid organ transplantation, Nat. Rev. Nephrol. 10 (12) (2014) 725.

[30] N.S. Alakulppi, L.E. Kyllönen, V.T. Jäntti, I.H. Matinlauri, J. Partanen, K.T. Salmela, J.T. Laine, Cytokine gene polymorphisms and risks of acute rejection and delayed graft function after kidney transplantation, Transplantation 78 (10) (2004) 1422-1428.

[31] B. Kruger, S. Krick, N. Dhillon, S.M. Lerner, S. Ames, J.S. Bromberg, M. Lin, L. Walsh, J. Vella, M. Fischereder, Donor Toll-like receptor 4 contributes to ischemia and reperfusion injury following human kidney transplantation, Proc. Natl. Acad. Sci. 106 (9) (2009) 3390-3395.

[32] J. Grinyo, Y. Vanrenterghem, B. Nashan, F. Vincenti, H. Ekberg, K. Lindpaintner, M. Rashford, C. Nasmyth-Miller, A. Voulgari, O. Spleiss, Association of four DNA polymorphisms with acute rejection after kidney transplantation, Transpl. Int. 21 (9) (2008) 879-891.

[33] M. Eikmans, I. de Canck, P. van der Pol, C.C. Baan, G.W. Haasnoot, M.J. Mallat, M. Vergunst, E. de Meester, J.I. Roodnat, J.D. Anholts, The functional polymorphism Ala258Ser in the innate receptor gene ficolin-2 in the donor predicts improved renal transplant outcome, Transplantation 94 (5) (2012) 478-485.

[34] K.M. Brown, E. Kondeatis, R.W. Vaughan, S.P. Kon, C.K. Farmer, J.D. Taylor, X. He, A. Johnston, C. Horsfield, B.J. Janssen, Influence of donor C3 allotype on late renaltransplantation outcome, N. Engl. J. Med. 354 (19) (2006) 2014-2023.

[35] M. Varagunam, M.M. Yaqoob, B. Döhler, G. Opelz, C3 polymorphisms and allograft outcome in renal transplantation, N. Engl. J. Med. 360 (9) (2009) 874-880.

[36] R.P. O'brien, P.J. Phelan, J. Conroy, P. O'kelly, A. Green, M. Keogan, D. O'neill, S. Jennings, C. Traynor, J. Casey, A genome-wide association study of recipient genotype and medium-term kidney allograft function, Clin. Transpl. 27 (3) (2013) 379-387.

[37] H.K. Pihlstrøm, G. Mjøen, S. Mucha, G. Haraldsen, A. Franke, A. Jardine, B. Fellström, H. Holdaas, E. Melum, Single nucleotide polymorphisms and longterm clinical outcome in renal transplant patients: a validation study, Am. J. Transplant. 17 (2) (2017) 528-533.

[38] L. Ghisdal, C. Baron, Y. Lebranchu, O. Viklický, A. Konarikova, M. Naesens, D. Kuypers, M. Dinic, E. Alamartine, G. Touchard, Genome-wide association study of acute renal graft rejection, Am. J. Transplant. 17 (1) (2017) 201-209.

[39] P. Sham, J.S. Bader, I. Craig, M. O'Donovan, M. Owen, DNA pooling: a tool for largescale association studies, Nat. Rev. Genet. 3 (11) (2002) 862

[40] M.L. Sanders, J.H. Karnes, J.C. Denny, D.M. Roden, T.A. Ikizler, K.A. Birdwell, Clinical and genetic factors associated with cutaneous squamous cell carcinoma in kidney and heart transplant recipients, Transplant. Direct 1 (4) (2015).

[41] J.A. McCaughan, A.J. McKnight, A.P. Maxwell, Genetics of new-onset diabetes after transplantation, J. Am. Soc. Nephrol. 25 (5) (2014) 1037-1049.

[42] A. Sato-Otsubo, Y. Nannya, K. Kashiwase, M. Onizuka, F. Azuma, Y. Akatsuka, Y. Ogino, M. Satake, M. Sanada, S. Chiba, Genome-wide surveillance of mismatched alleles for graft versus host disease in stem cell transplantation, Blood 126 (25) (2015) 2752-2763.

[43] A. Heinold, G. Opelz, S. Scherer, A. Ruhenstroth, G. Laux, B. Doehler, T. Tran, Role 
of minor histocompatibility antigens in renal transplantation, Am. J. Transplant. 8 (1) (2008) 95-102.

[44] L. Mesnard, T. Muthukumar, M. Burbach, C. Li, H. Shang, D. Dadhania, J.R. Lee, V.K. Sharma, J. Xiang, C. Suberbielle, Exome sequencing and prediction of longterm kidney allograft function, PLoS Comput. Biol. 12 (9) (2016) e1005088.

[45] R. Reindl-Schwaighofer, A. Kainz, B. Cole, J. van Setten, K. Jelencsics, B. Keating, R. Oberbauer, Alloimmunity through non-HLA epitopes in kidney transplantation, Am. J. Transplant. (2016) 708 Wiley-blackwell 111 river st, hoboken 07030-5774, nj USA.

[46] D.B. Goldstein, Common genetic variation and human traits, N. Engl. J. Med. 360
(17) (2009) 1696.

[47] J.A. Riancho, Genome-wide association studies (GWAS) in complex diseases: ad vantages and limitations, Reumatol. Clín. (English Ed.) 8 (2) (2012) 56-57.

Jianxin Yang, Frans H.J. Claas, Michael Eikmans* Dept. of Immunohematology and Blood Transfusion, Leiden University Medical Center, Leiden, The Netherlands E-mail address: M.Eikmans@lumc.nl

* Corresponding author at: Department of Immunohematology and Blood Transfusion, Leiden University Medical Center, Building 1, E3-Q, Albinusdreef 2, 2333 ZA Leiden, The Netherlands. 